\title{
Short communication: A missense mutation in the PROP1 (prophet of Pit 1) gene affects male fertility and milk production traits in the US Holstein population
}

\author{
X. Y. Lan, ${ }^{*} †$ F. Peñagaricano, $†$ L. DeJung, † K. A. Weigel, $\ddagger$ and H. Khatib† ${ }^{1}$ \\ ${ }^{*}$ College of Animal Science and Technology, Northwest A\&F University, Yangling, Shaanxi Province, 712100, China \\ †Department of Animal Sciences, and \\ ‡Department of Dairy Science, University of Wisconsin-Madison, Madison 53706
}

\begin{abstract}
In previous studies, we reported significant associations of the POU1F1 pathway genes with reproduction and production traits in several dairy cattle populations. Polymorphisms in genes of this pathway were found to be associated with both female and male fertility traits in dairy cattle. The POU1F1 gene is a direct downstream target for the regulation of the prophet of Pit1 (PROP1) gene, also known as PROP paired-like homeobox 1 . Interestingly, the position of PROP1 coincides with a quantitative trait locus affecting ovulation rate in cattle. Therefore, the objective of this study was to investigate whether PROP1 affects fertility and milk production traits in Holstein cattle. Using the DNA pooling sequencing approach, a missense single nucleotide polymorphism that replaces a histidine amino acid with an arginine was detected in exon 3 of PROP1. The arginine allele was found to be associated with a decrease in sire conception rate and an increase in productive life, protein yield, and net merit index in a population of 1,951 Holstein bulls. The transcription factors produced from the histidine and arginine isoforms are known to have different transcription, DNA binding, and regulation activities. As such, we propose that the association of the arginine isoform with decreased bull fertility is likely caused by reduced activity of this allele in male functions. The findings of this study suggest PROP1 polymorphisms as candidates in selection programs for fertility, health, and milk production traits in dairy cattle.
\end{abstract}

Key words: PROP1, sire conception rate, milk production, association

\section{Short Communication}

During the past several decades, powerful and effective selection strategies focusing on milk yield and

Received August 1, 2012.

Accepted November 2, 2012.

${ }^{1}$ Corresponding author: hkhatib@wisc.edu related measures in dairy cattle have led to significant increases in milk production and, simultaneously, to a rapid decline in reproductive efficiency of high-producing cows (Dobson et al., 2007). Thus, several countries are now including female fertility in their breeding goals and selection programs (Miglior et al., 2005). Although both cows and bulls contribute to reproductive efficiency, male fertility has received much less consideration compared with that of females. Furthermore, several studies have reported that bull subfertility accounts for a significant percentage of reproductive failure in dairy cattle (DeJarnette et al., 2004). Therefore, the identification of genetic markers and a better understanding of the molecular mechanisms involved in bull subfertility and milk production would help to restore reproductive performance and maintain high milk production of dairy cows through marker-assisted selection schemes (Beerda et al., 2008).

Although it is well established that intensive selection for milk production traits in dairy cattle has led to a significant decline in cow fertility (Washburn et al., 2002; López-Gatius, 2003; Dobson et al., 2007), limited information can be found on the molecular mechanisms or genes affecting both milk traits and reproductive performance. Recently, we reported associations of the POU1F1 pathway genes (POU1F1, GH, PRL, GHR, PRLR, STAT5A, OPN, and UTMP) with different milk production traits and early embryonic survival and fertilization rate as measures of female fertility (Khatib et al., 2009). In a subsequent study, some genes of the POU1F1 pathway were also found to be associated with male fertility in a Holstein bull population (Khatib et al., 2010). The POU1F1 gene, a key gene in the POU1F1 pathway, is regulated by the prophet of Pit-1 (PROP1) transcription factor gene, and mutations in these 2 genes have significant effects on pituitary development in human and mouse (Davis et al., 2010). The PROP1 gene is specifically expressed in the pituitary gland, and it plays an important role in the ontogenesis of pituitary gonadotropes, somatotropes, lactotropes, and caudomedial thyrotropes (Davis et al., 2010). Fur- 
thermore, the bovine PROP1 gene is located at a QTL on chromosome 7 that affects ovulation rate in cattle (Kappes et al., 2000; Kirkpatrick et al., 2000). Therefore, the objective of this study was to identify SNP in PROP1 and test their associations with fertility and production traits in a Holstein dairy cattle population.

A DNA pooling sequencing approach was used (Khatib et al., 2008) to identify genetic variants in the $5^{\prime}$ untranslated region (UTR), exons, introns, and 3' UTR of PROP1 (Gene ID: 282563; http://refgene. com/gene/282563). Five pairs of primer sequences were designed using Primer Premier Software (version 5.0, Premier Biosoft International, Palo Alto, CA). The sequence information of the 5 pairs of primers is shown in Supplementary Table S1 (available online at http:// www.journalofdairyscience.org/). Pools of DNA (n = 3 ) were constructed from 20 random semen samples with equal amounts of DNA and amplified with the 5 pairs of primers each. The amplified PCR products were sequenced and SNP were identified by visually inspecting sequence traces. The PCR amplification and sequencing were performed as described in Khatib et al. (2008). Analysis using BLASTN (http://blast. ncbi.nlm.nih.gov/) of the PCR product amplified with $\mathrm{P} 4$ primers identified a missense $\operatorname{SNP}(\mathrm{A} / \mathrm{G})$ in exon 3 that alters histidine 173 to arginine (p.His173Arg). The SNP (rs136195618) is located on chromosome 7 at position 41,208,950 according to the UMD3.1 Bovine Genome Assembly (Zimin et al., 2009).

A total of 255 Holstein bull semen samples were obtained from Genex Cooperative/CRI (Shawano, WI). Genomic DNA was isolated using standard phenol/ chloroform protocols, and then diluted to a concentration of $25 \mathrm{ng} / \mu \mathrm{L}$ for DNA genotyping. The PCR amplification products of $\mathrm{P} 4$ primers were digested with $5 \mathrm{U}$ of $\mathrm{NlaIII}$ (Promega, Madison, WI) for $5 \mathrm{~h}$ at $37^{\circ} \mathrm{C}$ following the manufacturer's protocol. The digested products were detected by electrophoresis in $2.0 \%$ agarose gel stained with ethidium bromide. The $\mathrm{G}$ allele (cut allele) was indicated by bands at 205, 114, and 46 $\mathrm{bp}$, and the uncut allele A was indicated by bands at 325 and $46 \mathrm{bp}$.

The p.His173Arg SNP was first genotyped in 255 Genex bulls (i.e., the reference population), and then imputed in a total of 1,696 individuals (i.e., the imputed population) so that a final data set of 1,951 bulls with genotypic data was generated for subsequent statistical analyses. The imputation of this genetic marker was based on 100 SNP on each side of PROP1, which were previously genotyped in both the reference and the imputed populations using the Illumina BovineSNP50 Bead Chip (Illumina Inc., San Diego, CA). Imputation was performed using the population-based haplotype clustering algorithm of Scheet and Stephens (2006), implemented via fastPHASE version 1.2 software using the default settings for all parameters (University of Washington TechTransfer Digital Ventures Program, Seattle, WA). The distribution of p.His173Arg SNP genotypes in the total bull population was AA ( $\mathrm{n}=$ 1,767), AG ( $\mathrm{n}=170)$, and $\mathrm{GG}(\mathrm{n}=14)$.

Estimated breeding values of milk yield $(\mathrm{kg})$, milk fat and protein yields $(\mathrm{kg})$, milk fat and protein percentages (\%), somatic cell score, daughter pregnancy rate (\%), sire conception rate (SCR, \%), productive life (mo), and net merit index $(\$)$ of the 1,951 bulls were provided by the Animal Improvement Programs Laboratory of the United States Department of Agriculture (AIPLUSDA, Beltsville, MD). Association between the SNP and each trait was analyzed using the following mixed linear model:

$$
y_{i j k}=\mu+\beta \mathrm{SNP}_{j}+\operatorname{sire}_{k}+\mathrm{e}_{i j k},
$$

where $y_{i j k}$ represents the EBV from the $i$ th animal $(i=$ $1,2, \ldots, 1,951)$ for the trait under consideration, $\mu$ is the general mean, $\mathrm{SNP}_{j}$ is the number of copies of 1 allele of the SNP (corresponding to 0,1 , or 2 copies) carried by the $i$ th animal, $\beta$ is the regression coefficient for the SNP considered (also known as the allele substitution effect), sire $_{k}$ represents the random additive genetic effect of the $k$ th sire $(k=1,2, \ldots, 246)$ of the $i$ th animal, and $\mathrm{e}_{i j k}$ represents the random residual for each observation. For SCR, the statistical model also included the effect of the AIPL-USDA SCR evaluation (fixed effect with 7 levels) from which the SCR value was obtained: SCR data were obtained from 7 consecutive evaluations between August 2008 and December 2010 and, for those bulls with multiple evaluations, the most recent SCR evaluation of the bull was used in the analysis. The distribution of sire ${ }_{k}$ and $\mathrm{e}_{i j k}$ was assumed as $N\left(0, \mathbf{A} \sigma_{a}^{2}\right)$ and $N\left(0, \mathbf{W}^{-1} \sigma_{e}^{2}\right)$, respectively, where $\mathbf{A}$ represents the matrix of additive relationships between sires in the pedigree $(1,558 \times 1,558)$, and $\mathbf{W}$ is a diagonal matrix of order 1,951 with its elements representing reliabilities of EBV. Association between the SNP and each trait was tested using a likelihood ratio test compared with a reduced model without the SNP effect. In all analyses, EBV were weighted by their reliability values to correct for differences in their accuracies. All analyses were performed using the pedigreemm package (Vazquez et al., 2010) of the $\mathrm{R}$ language/environment (R Development Core Team, 2009).

Table 1 shows that 1 copy of allele $\mathrm{G}$ of PROP 1 is associated with a decrease of $0.39 \%$ in SCR and an increase in productive life $(0.43 \mathrm{mo})$, protein yield (1.13 $\mathrm{kg}$ ), and total index (\$46.7) compared with allele A. Milk yield, daughter pregnancy rate, SCS, fat yield percentage, and protein percentage did not show signifi- 
Table 1. Association between the p.His173Arg polymorphism of PROP1 gene and sire conception rate and productive traits in the US Holstein bull population

\begin{tabular}{lcr}
\hline Trait & $\begin{array}{c}\text { Allele substitution } \\
\text { effect }(\mathrm{A} \text { to } \mathrm{G}) \pm \mathrm{SE}\end{array}$ & $P$-value \\
\hline Sire conception rate $(\%)$ & $-0.39 \pm 0.02$ & 0.0075 \\
Productive life $(\mathrm{mo})$ & $0.43 \pm 0.02$ & 0.0031 \\
Protein $(\mathrm{kg})$ & $1.13 \pm 0.51$ & 0.0252 \\
Net merit index $(\$)$ & $46.7 \pm 1.3$ & $<0.0001$ \\
\hline
\end{tabular}

cant associations with the PROP1 SNP. The exact test for Hardy-Weinberg test revealed that this SNP is in disequilibrium $(P=0.0003)$ in the Holstein bull population, implying that intensive selection for milk production traits has affected the allelic balance of $P R O P 1$ polymorphisms. The association of PROP1 with SCR confirms previous results of some of the POU1F1 pathway genes, which are regulated by PROP1, with bull fertility (Khatib et al., 2010).

Interestingly, the 2 alleles of the p.His173Arg SNP encode 2 isoform transcription factors that differ in their DNA binding and gene regulatory activities (Showalter et al., 2002). In vitro transcription and translation analysis revealed a 5 -fold reduction in DNA binding of the arginine isoform compared with the histidine isoform of PROP1 (Showalter et al., 2002). Thus, the association of the arginine isoform ( $\mathrm{G}$ allele) with decreased SCR may indicate impaired transcription, DNA binding ability, or activation capacity of this allele in male fertility functions. Allele $\mathrm{G}$ of PROP 1 was also significantly associated with increases in milk production and health traits. This antagonistic relationship between milk production and fertility found for PROP1 alleles has been observed for several genes from the PROP1/POU1F1 pathway (Khatib et al., 2009). However, the molecular mechanisms by which some alleles affect antagonistic traits are not clear. Indeed, Showalter et al. (2002) proposed that PROP1 could have both positive and negative transcriptional activities, depending on the transcriptional partner proteins interacting with the gene. Thus, PROP1 can affect both SCR and milk production traits simultaneously.

Given the importance of the functional p.His173Arg SNP and the association of this SNP with reproduction and production traits in cattle, combined with the fact that PROP1 is located in a QTL region affecting ovulation rate (Kappes et al., 2000; Kirkpatrick et al., 2000), this functional SNP could be used in selection programs to improve economically important traits in cattle.

\section{ACKNOWLEDGMENTS}

The study was supported by USDA Hatch grant WIS-142-PRJ17PH from the University of Wisconsin-
Madison. The authors thank Genex Cooperative/CRI (Shawano, WI) for providing genotypic and phenotypic data. Xianyong Lan was supported by the Chinese Scholarship Council (CSC, Beijing, China).

\section{REFERENCES}

Beerda, B., J. Wyszynska-Koko, M. F. W. te Pas, A. A. C. de Wit, and R. F. Veerkamp. 2008. Expression profiles of genes regulating dairy cow fertility: Recent findings, ongoing activities and future possibilities. Animal 2:1158-1167.

Davis, S. W., F. Castinetti, L. R. Carvalho, B. S. Ellsworth, M. A. Potok, R. H. Lyons, M. L. Brinkmeier, L. T. Raetzman, P. Carninci, A. H. Mortensen, Y. Hayashizaki, I. J. P. Arnhold, B. B. Mendonc, T. Brue, and S. A. Camper. 2010. Molecular mechanisms of pituitary organogenesis: In search of novel regulatory genes. Mol. Cell. Endocrinol. 323:4-19.

DeJarnette, J. M., C. E. Marshall, R. W. Lenz, D. R. Monke, W. H. Ayars, and C. G. Sattler. 2004. Sustaining the fertility of artificially inseminated dairy cattle: The role of selection indices in Holstein cattle of various countries. J. Dairy Sci. 88:1255-1263.

Dobson, H., R. Smith, M. Royal, Ch. Knight, and I. Sheldon. 2007. The high-producing dairy cow and its reproductive performance. Reprod. Domest. Anim. 42(Suppl. 2):17-23.

Kappes, S. M., G. L. Bennett, J. W. Keele, S. E. Echternkamp, K. E. Gregory, and M. Thallman. 2000. Initial results of genomic scans for ovulation rate in a cattle population selected for increased twinning rate. J. Anim. Sci. 78:3053-3059.

Khatib, H., W. Huang, X. Wang, A. H. Tran, A. B. Bindrim, V. Schutzkus, R. L. Monson, and B. S. Yandell. 2009. Single gene and gene interaction effects on fertilization and embryonic survival rates in cattle. J. Dairy Sci. 92:2238-2247.

Khatib, H., R. L. Monson, W. Huang, R. Khatib, V. Schutzkus, H. Khateeb, and J. J. Parrish. 2010. Validation of in vitro fertility genes in a Holstein bull population. J. Dairy Sci. 93:2244-2249.

Khatib, H., R. L. Monson, V. Schutzkus, D. M. Kohl, G. J. M. Rosa, and J. J. Rutledge. 2008. Mutations in the STAT5A gene are associated with embryonic survival and milk composition in cattle. J. Dairy Sci. 91:784-793.

Kirkpatrick, B. W., B. M. Byla, and K. E. Gregory. 2000. Mapping quantitative trait loci for bovine ovulation rate. Mamm. Genome 11:136-139.

López-Gatius, F. 2003. Is fertility declining in dairy cattle? A retrospective study in northeastern Spain. Theriogenology 60:89-99.

Miglior, F., B. L. Muir, and B. J. Van Doormaal. 2005. Selection indices in Holstein cattle of various countries. J. Dairy Sci. 88:12551263.

R Development Core Team. 2009. R: A Language and Environment for Statistical Computing. R Foundation for Statistical Computing, Vienna, Austria.

Scheet, P., and M. Stephens. 2006. A fast and flexible statistical model for large-scale population genotype data: Applications to inferring missing genotypes and haplotypic phase. Am. J. Hum. Genet. 78:629-644.

Showalter, A. D., T. P. Smith, G. L. Bennett, K. W. Sloop, J. A. Whitsett, and S. J. Rhodes. 2002. Differential conservation of transcriptional domains of mammalian prophet of pit-1 proteins revealed by structural studies of the bovine gene and comparative functional analysis of the protein. Gene 291:211-221.

Vazquez, A. I., D. M. Bates, G. J. M. Rosa, D. Gianola, and K. A. Weigel. 2010. Technical note: An R package for fitting generalized linear mixed models in animal breeding. J. Anim. Sci. 88:497-504.

Washburn, S. P., W. J. Silvia, C. H. Brown, B. T. McDaniel, and A. J. McAllister. 2002. Trends in reproductive performance in southeastern Holstein and Jersey DHI herds. J. Dairy Sci. 85:244-251.

Zimin, A. V., A. L. Delcher, L. Florea, D. R. Kelley, M. C. Schatz, D. Puiu, F. Hanrahan, G. Pertea, C. P. Van Tassell, T. S. Sonstegard, G. Marçais, M. Roberts, P. Subramanian, J. A. Yorke, and S. L. Salzberg. 2009. A whole-genome assembly of the domestic cow, Bos taurus. Genome Biol. 10:R42. 